\section{A qualidade da interação entre pares e a implantação de um ambiente sociomoral cooperativo a partir da literatura infantil ${ }^{1}$}

\section{The interaction quality between pairs and the implantation of a cooperative social and moral environment starting from the children's literature}

\begin{abstract}
Anna Karolina Santoro Borges é pedagoga, especialista em Relações Interpessoais e Construção da Autonomia na Escola pela Universidade de Franca (Unifran) e membro do Grupo de Estudos e Pesquisas em Educação Moral (GEPEM - Unicamp/UNESP).
\end{abstract}

\section{Contato: anna_borges@ig.com.br}

Luciene Regina Paulino Tognetta é doutora em Psicologia Escolar pela Universidade de São Paulo (USP) e vice-líder do Grupo de Estudos e Pesquisas em Educação Moral (GEPEM - Unicamp/ UNESP).

\section{Contato: Irpaulino@uol.com.br}

\section{Resumo}

A presente investigação, de caráter qualitativo, objetivou verificar possíveis mudanças nas relações entre pares após a implantação de um trabalho com literatura infantil. Tal trabalho foi decorrente de um projeto de formação de professores cuja proposta é a implantação de um ambiente sociomoral cooperativo em sala de aula. A amostra intencional foi composta por 250 alunos (meninos e meninas) de 7 a 10 anos, todos estudantes do ensino fundamental I de redes municipais do Estado de São Paulo. 0 método utilizado consistiu na aplicação de um questionário em duas etapas: o pré-teste, anterior à implantação do projeto, e o pós-teste, preenchido pelas crianças após o término do trabalho. Por meio de um questionário que continha perguntas sobre três temas principais - as
1. Participaram dessa pesquisa Brunna Talita Rodrigues, Lariely Gobetti e Vanessa Cristina Alves Aranha Morimoto, todas especialistas em Relações interpessoais e construção da autonomia na escola pela Unifran. 
amizades na escola, a sistemática dos trabalhos em grupo e os sentimentos expressos a respeito do ambiente escolar -, as crianças foram indagadas sobre a qualidade de suas relações entre pares. Os dados obtidos passaram por uma análise quantitativa e qualitativa, sendo estatisticamente tratados. Os resultados do pré-teste e pós-teste foram comparados, e foi possível constatar a partir daimplantação do trabalho com literatura infantil, melhor qualidade nas relações interpessoais vivenciadas na escola.

Palavras-chave: literatura infantil; ambiente sociomoral cooperativo; procedimentos de educação moral; afetividade; personalidade ética.

\section{Abstract}

The present research, of a qualitative nature, aimed to check possible changes in the relations between pairs after the implantation of a work with children's literature. The work was part of a teacher training project whose proposal is the deployment of a cooperative sociomoral environment in the classroom. The sample was composed of 250 students (boys and girls) 7-10 years, students of elementary school I in municipal education networks in São Paulo State. The method used was the application of a questionnaire in two stages: the pre-test, prior to the implementation of the project, and the post-test, carried out with the children after the end of the work. By means the questionnaire, that contained questions on three main themes - friendships at school, the systematic group work and the feelings expressed with respect to the school -, the children were asked about the quality of the relations between pairs. The data obtained have gone through a quantitative and qualitative analysis, being statistically proven. Eventually, the results of the two stages of the questionnaire were compared, indicating a better quality in interpersonal relations experienced in school after the implementation of the work with children's literature.

Keywords: children's literature; cooperative sociomoral environment; procedures for moral education; affection; ethical personality. 


\section{Introdução}

Um dos objetivos que as instituições de ensino têm em destaque é a autonomia por parte de seus alunos. Contudo, a conquista de tal objetivo tem se mostrado ineficaz pelo conjunto de ações da escola, que, ao contrário da promoção da autonomia de seus alunos, tem promovido apenas maior submissão à autoridade e limitado, suas próprias descobertas, ainda que no limiar de um novo século. As pesquisas de Dubet (1997) e Debarbieux (2006) dão-nos notáveis exemplos de como a qualidade das relações na escola é diminuída quando os educadores pouco sabem sobre como favorecê-la. Não pairam dúvidas de que educadores em geral aspiram à formação ética de seus alunos, desejando que estes sejam respeitosos, justos, generosos. Entretanto, eles desconhecem que tais valores morais são formados no cotidiano das relações interpessoais e, portanto, não são estruturas inatas, tampouco apenas interiorizadas por aqueles que aprendem (PIAGET, 1932).

Assim, torna-se necessária uma reflexão sobre a prática pedagógica que possa de fato formar sujeitos mais éticos, cujas relações interpessoais sejam baseadas no respeito mútuo. Por certo, um desses caminhos, visto como uma oportunidade de construção de valores da criança que age, é o trabalho com as histórias infantis que permeiam o imaginário das crianças e podem impulsionar a exploração de temas ligados ao desenvolvimento moral e à construção de valores (MEYER, 1995).

Certamente, a literatura infantil tem uma importante e fundamental tarefa para cumprir nesta sociedade em mudança: "a de servir como agente de transformação, seja no espontâneo convívio leitor/livro, seja no diálogo leitor/texto estimulado pela escola" (COELHO, 2000, p. 15). Segundo Coelho (1982, p. 3) "é ela, dentre as diferentes manifestações da Arte, a que atua de maneira mais profunda e duradoura, no sentido de dar forma e de divulgar os valores culturais que dinamizam uma sociedade ou uma civilização".

A literatura infantil é defendida por diversos autores como uma ferramenta útil para a educação moral, processo pelo qual as crianças desenvolvem um entendimento crescente sobre o que é certo e o que é errado e, dessa forma, desenvolvem também a capacidade de pensar criticamente sobre o fato de que suas ações afetam o bem-estar das outras pessoas (EPSTEIN, 2003).

Nesse sentido, o contato com diferentes personagens e suas histórias pode favorecer a aprendizagem de formas mais 
equilibradas de relacionamento entre as crianças, na medida em que proporciona uma reflexão sobre as ações e as trocas entre os protagonistas e impulsiona a experiência de pensar sobre suas próprias ações na convivência com os outros. Impulsionados por investigações anteriores que admitem tal importância, a proposta deste artigo consiste em apresentar uma investigação cujo objetivo é constatar se haveria mudanças na convivência entre as crianças inseridas num projeto de intervenção que se utiliza da literatura infantil como instrumento.

\section{Contextualização}

Encontramos diferentes discussões que reiteram a importância da literatura infantil na perspectiva aqui adotada. Krogh e Lamme (1985), Clare e Gallimore (1996) apontam o poder da literatura infantil como uma estratégia eficaz para fomentar as discussões das histórias e promover o desenvolvimento moral das crianças. Por meio da literatura, lembraria ainda Epstein (2003), as crianças podem observar a vida das pessoas, suas experiências, seus dilemas cotidianos. Jalongo (2004) e Lowe (2009) afirmam que a literatura pode auxiliar na discussão de temas difíceis, tais como o bullying, a morte, o abuso e as perdas em geral, proporcionando aos alunos uma espécie de apoio emocional e social para que possam, identificando-se com os personagens, enfrentar suas próprias dificuldades.

Numa investigação com crianças de 6 anos, Oliveira (1994) aponta a importância da literatura infantil para a evolução do princípio de justiça. Os dados de sua pesquisa elucidaram o quanto se pode, pela promoção de conflitos cognitivo-morais, favorecer o desenvolvimento moral das crianças. Contudo, a autora já lembrava que só seria possível chegar a esse resultado por meio de práticas e posturas de professores que trabalhassem propondo experiências e situações de conflitos morais, de modo que as crianças vivenciassem e pensassem sobre eles.

Certamente, a partir das histórias no ambiente escolar, as crianças podem ter momentos únicos de discussão moral e oportunidades para expressar seus sentimentos. Quando podem discutir sobre as ações dos personagens, sobre como estes se sentem na trama em que estão envolvidos, as crianças experienciam um excelente exercício de sair de um único ponto de vista e considerar as diferenças.

O fato é que somente contar histórias ou proporcionar o contato das crianças com a literatura infantil sem que um trabalho efetivo 
seja realizado pode, na maioria das vezes, não propiciar o esperado desenvolvimento, uma vez que é preciso vivenciar a experiência de se autorregular. Isso porque a moral autônoma tão pretendida pela escola, assim como defendeu Piaget em toda sua obra, depende de um processo de autorregulação do próprio sujeito que age e, portanto, de que a tomada de consciência das ações num conflito e o controle das próprias emoções sejam realizados pelas crianças e não pelo professor, quando resolve por elas os problemas que têm em suas relações interpessoais.

Rosário, Núnez e González-Pienda (2005), Whitebread et al. (2005) e outros autores sugerem que as crianças podem aprender a se autorregularem por meio da narração de histórias. Também Epstein (2003) comprovou que a capacidade de autorregulação das crianças é desenvolvida quando a elas são proporcionados momentos de reflexão em que podem pensar sobre as questões que afloram da literatura infantil.

Assim, a literatura pode ser uma ferramenta eficaz para proporcionar o desenvolvimento moral das crianças e a qualidade do ambiente vivenciado por elas. Num espaço cujas relações interpessoais são baseadas na cooperação, em sua acepção piagetiana (PIAGET, 1969; BAGAT, 1986; MENIN, 1996), ou seja, no diálogo e na oportunidade de tomar decisões, fazer escolhas e manifestar sentimentos, torna-se possível a construção do autorrespeito, primordial para que o respeito ao outro esteja presente. Nesse mesmo ambiente, refletir sobre as histórias, identificar-se com um ou outro personagem e generalizar as mesmas situações para as circunstâncias de sua própria vida são algumas das possibilidades irrestritas do trabalho com a literatura. São formas pelas quais meninos e meninas podem identificarse com valores centrais como a justiça, o respeito, a amizade, o perdão e a honestidade, valores estes não transmitidos por lições, mas aprendidos por meio da vivência (ZIBERMAN, 2003).

É preciso lembrar que todo ambiente escolar, seja ele cooperativo ou não, influencia o desenvolvimento dos que nele estão inseridos, ainda que não intencionalmente, fazendo parte, dessa forma, do currículo oculto de toda instituição de ensino. Quanto mais autoritário e coercitivo for esse ambiente, mais ele dará margem para a formação de indivíduos conformistas e submissos.

Diante de tais prerrogativas, é possível indagar: haveria mudanças nas relações que as crianças vivenciam entre pares com a implantação de uma proposta em que as questões de convivência são trabalhadas a partir da literatura infantil? 
Passemos a apresentar a investigação que pretendeu responder a essa pergunta.

\section{Método}

A hipótese que guiou esta investigação foi a de que a implantação de um trabalho com literatura infantil poderia promover uma mudança na qualidade das relações interpessoais entre crianças. 0 objetivo desta pesquisa foi constatar tais possibilidades de mudança na visão dos próprios alunos.

Trata-se de uma pesquisa de campo, com abordagem qualitativa e quantitativa, que buscou avaliar as mudanças na convivência entre as crianças - de acordo com o julgamento delas - a partir de um projeto financiado pelo governo do Estado de São Paulo e implantado em duas redes municipais de educação escolhidas intencionalmente pelos patrocinadores. Participaram do projeto 70 professores de ensino fundamental I (que corresponde aos cinco primeiros anos de escolaridade da educação básica) e 2.500 alunos desse mesmo segmento; contudo, a amostra para a presente investigação foi composta por $10 \%$ desse grupo de alunos, ou seja, 250 crianças de 7 a 10 anos, sendo 125 meninos e 125 meninas.

A implantação deste trabalho com literatura infantil consistiu na promoção de um curso de formação de educadores e na distribuição de três livros de literatura infantil. Em síntese, os três livros são fundamentados em investigações que constatam a necessidade da construção do autorrespeito e do respeito ao outro como imprescindíveis à convivência. Por meio da história de um menino-rei, destaca-se que o respeito por si é conquista progressiva de quem pode escolher, pode dizer o que sente, pode participar ativamente da construção de sua própria rotina diária; é, portanto, formado a partir de diferentes oportunidades de convivência consigo mesmo e com os outros. Nessas ocasiões, meninos e meninas podem tomar consciência de seus próprios desejos, de como se sentem e de como os outros se sentem quando podem ouvir do outro, quando podem dizer para o outro aquilo que pensam. Por certo, as experiências capazes de proporcionar esse movimento de autoconhecimento e de conhecimento do outro são necessárias para aqueles que precisam e podem evoluir moralmente. Tais experiências não são suficientes, mas são importantes passos para que valores morais como respeito, generosidade, justiça e tolerância sejam incorporados às suas identidades. 
0 curso aos professores foi ministrado por especialistas em Psicologia Moral integrantes do Grupo de Estudos e Pesquisas em Educação Moral (GEPEM) da Universidade Estadual de Campinas (Unicamp) e teve 50 horas de duração.. Durante as aulas, os professores discutiram sobre agressões físicas e verbais, furtos, desobediência às normas e os constantes problemas cotidianos na relação entre as próprias crianças e entre elas e o professor. Tratou-se de repensar os objetivos da escola - que são relativos à formação de pessoas mais autônomas, mais responsáveis e respeitosas - e discutir as ações que podem ser realizadas a fim de se atingir tal objetivo. À luz de um referencial teórico interacionista difundido pelo GEPEM, cujas investigações no campo da psicologia e da educação moral contribuem para o entendimento das ações cotidianas que a escola deve e pode desenvolver, foram abordadas perguntas como: Como contribuir de fato para que os tão sonhados objetivos sejam atingidos? 0 que falta para que essas conquistas sejam alcançadas? Falta a família? Faltam regras? Faltam valores?

A proposta foi discutir a implantação na escola de um projeto de convivência em que as crianças sejam sujeitos ativos e possam falar sobre o que sentem e o que pensam. Assim, a organização de assembleias, estratégias de organização de avaliação do dia as estratégias de intervenção diante dos conflitos interpessoais foram tratadas a partir de histórias da literatura infantil em que tais ações eram sugeridas. Os livros foram utilizados, portanto, como disparadores de discussões sobre a implantação de rotinas diferenciadas na escola: as rodas de avaliação, a linguagem usada para mediar um conflito, a organização das regras a partir de uma necessidade vivenciada pelo grupo de alunos etc.

Para averiguar, a partir do julgamento das crianças, as possíveis mudanças na convivência entre elas, utilizou-se como método a aplicação de um questionário escrito contendo perguntas fechadas. As questões abordavam três aspectos principais: 1) as amizades presentes na relação entre pares; 2) as oportunidades de troca e a experiência dos trabalhos em grupo; 3) os sentimentos com relação à escola.

Em relação ao primeiro aspecto, perguntamos: "Tem alguém na sua classe com quem você gosta de brincar?". As respostas poderiam ser dadas em quatro alternativas: a) com ninguém; b) com uma pessoa; c) com duas ou três pessoas; d) com todo mundo. Questionamos também: "Tem alguém na sua classe com quem você não gosta de brincar?". As alternativas de respostas para esse item eram: a) ninguém; b) uma pessoa; c) duas ou três pessoas; d) quatro a dez pessoas; e) todo mundo. 
Quanto às oportunidades de troca e à experiência dos trabalhos em grupo, perguntamos: "Tem alguém na sua classe que o incomoda com brincadeiras, empurrões, ou outras formas que o deixam chateado?". Para tanto, as seguintes alternativas eram possíveis: a) ninguém; b) uma ou duas pessoas; c) quatro a dez pessoas; d) todo mundo. Outro item se referiu à experiência de estar só: "Alguma vez você já se sentiu sozinho no recreio porque seus amigos não quiseram brincar com você?". Para essa questão, foram apresentadas as seguintes alternativas: a) nunca; b) somente uma vez; c) duas ou mais vezes; d) muitas vezes. Finalmente, perguntamos sobre os trabalhos em grupo: "Você já fez ou faz trabalhos em grupo em sua sala?". As alternativas foram: a) sempre faço trabalhos em grupo; b) de vez em quando a gente faz trabalhos em grupo e a professora escolhe os grupos; c) de vez em quando a gente faz trabalhos em grupo e a gente escolhe com quem quer ficar; d) já fizemos uma ou duas vezes trabalhos em grupo.

Quanto aos sentimentos experimentados com relação à escola, questionamos: "Com você se sente quando está nas aulas?". Para esse item, tivemos as seguintes alternativas: a) triste; b) alegre; c) chateado; d) com medo; e) com vontade de ir embora; f) irritado; g) entusiasmado; h) animado.

Antes de se iniciarem os trabalhos de formação de professores e antes que os livros fossem entregues às crianças atendidas pelo projeto, elas receberam o questionário para que pudessem responder: o pré-teste. Após a aplicação desse pré-teste, iniciouse a implantação do projeto. Durante quatro meses, os professores, ao mesmo tempo em que se encontravam para a formação semanal, adotavam as estratégias aprendidas no cotidiano de suas aulas, sempre orientados pelo docente do curso. Depois da implantação do projeto e do trabalho que os educadores realizaram em sala de aula com as crianças, o questionário contendo perguntas fechadas foi novamente aplicado: o pós-teste.

Os dados obtidos nessa coleta passaram por uma análise qualitativa e quantitativa das respostas encontradas. Os resultados do pré-teste e do pós-teste foram comparados e analisados estatisticamente por meio do teste de McNemar, para comparar duas proporções obtidas em amostras pareadas - antes e depois -, e do teste de simetria (uma extensão do teste de McNemar para três ou mais proporções pareadas). 0 objetivo era constatar se, na visão dos alunos, houve melhorias nas relações interpessoais vivenciadas na escola após a implantação do projeto. Passemos agora à apresentação e à discussão dos resultados encontrados. 


\section{Apresentação e discussão dos resultados}

A relação entre pares: como andam as amizades?

0 primeiro de nossos objetivos era saber se encontraríamos diferenças em relação aos problemas de convivência entre as crianças antes e depois da implantação do projeto. Com auxílio do gráfico 1, que apresenta as respostas para a pergunta "Tem alguém da sua classe com quem você gosta de brincar?", podemos notar mudanças significativas.

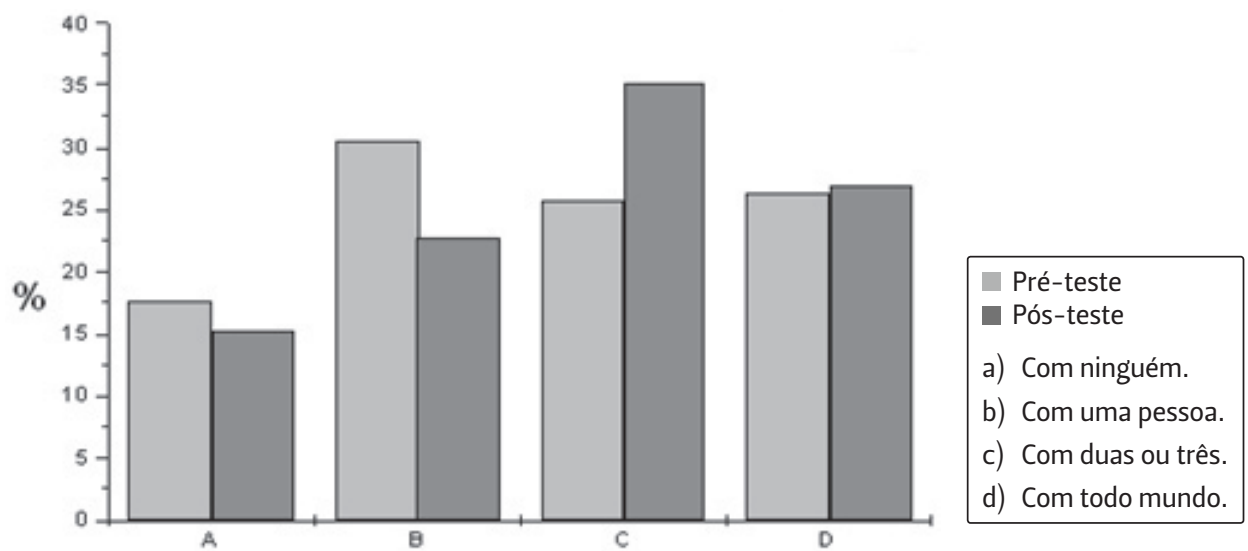

Gráfico 1 - Tem alguém da sua classe com quem você gosta de brincar?

Notemos que, no pré-teste, a maioria das crianças $(30,4 \%)$ preferia brincar com apenas uma pessoa; já no pós-teste; esse percentual é de $22,8 \%$ e a porcentagem de crianças que gostavam de brincar com duas ou três pessoas aumentou 9,6\%. Com a aplicação do teste de simetria $(p<0.01)$, constatamos que as diferenças entre pré e pós- teste foram estatisticamente significativas. Os resultados demonstram uma evolução no que diz respeito ao entrosamento das crianças entre os dois períodos de aplicação do questionário. Por certo, sabemos que há uma evolução natural para que tais relações se tornem mais eficazes com o tempo; contudo, podemos inferir que, em um ambiente cooperativo onde a convivência entre iguais é valorizada, as crianças aprendem a ser mais amigas, solidárias e tolerantes umas com as outras.

Durante muito tempo, os educadores acreditaram erroneamente que era um benefício para a criança trabalhar sempre sozinha, uma vez que isso a obrigava a pensar por si própria e exigia um posicionamento ante as questões. Piaget (1932), porém, em suas pesquisas mostrou o contrário: que o conhecimento se dá pela interação com o meio. Assim, o contato com o outro tem uma 
função imprescindível, tanto do ponto de vista intelectual quanto, neste caso, do ponto de vista das relações que são instituídas.

Perguntamos também para as crianças se havia alguém na classe com quem elas não gostavam de brincar. Não encontramos diferenças significativas entre pré e pós-teste quando aplicamos $o$ teste McNemar e o teste de simetria $(p=0,28)$. Contudo, se observarmos o gráfico 2 a seguir, podemos constatar algumas diferenças que nos chamam a atenção.

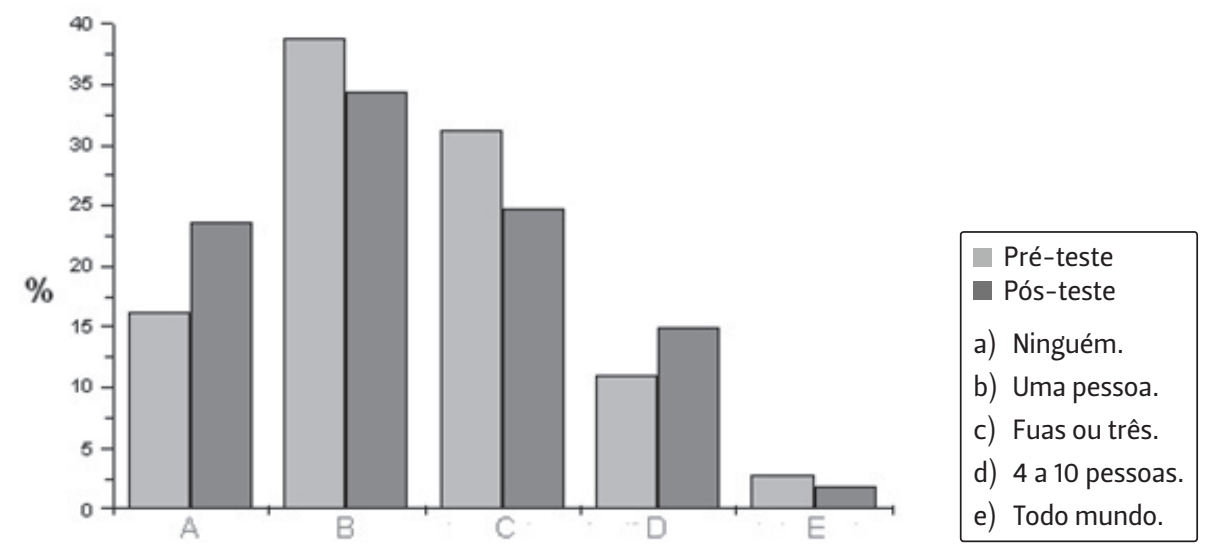

Gráfico 2 - Tem alguém da sua classe com quem você não gosta de brincar?

No pós-teste, houve uma porcentagem maior de crianças que disseram que não havia ninguém com quem não gostavam de brincar: o aumento foi de $7,7 \%$. A porcentagem diminuiu nas alternativas "uma pessoa" (4,46\%), "duas ou três" $(6,47 \%)$ e "todo mundo" ( $0,81 \%)$, embora, como dissemos, estatisticamente não haja relevância nessas diferenças. Somados os resultados de ambas as perguntas e consideradas essas ligeiras diferenças, porém, podemos afirmar que as crianças demonstram maior qualidade em suas relações de amizade, ainda que o método utilizado (somente duas questões para obter tais resultados) não possibilite mensurar com precisão as características dessas relações. Apenas inferimos, portanto, que o companheirismo e a generosidade fizeram-se mais presentes no pós-teste.

Tal experiência de melhor qualidade nas relações entre pares é relevante quando se pensa na possibilidade de evolução moral. Para Oliveira (2007, p. 102), uma moral heterônoma tende a desaparecer quando crianças e adolescentes têm a oportunidade de "vivenciar situações nas quais ocorram as trocas de experiências, de informações, de perspectivas diferentes que, embora divergentes, são embasadas no diálogo, na cooperação, na discussão e no respeito mútuo". 


\section{As oportunidades de troca e os trabalhos em grupo}

Para analisar as oportunidades de troca entre pares, questionamos as crianças quanto a brincadeiras ou incômodos/ problemas nas relações, perguntando: "Tem alguém da sua classe que o incomoda com brincadeiras, ameaças, empurrões ou outras formas que o deixam chateado?".

A partir da aplicação do teste de simetria, observamos que não há diferença significativa entre o pré e pós-teste $(p=0.17)$, conforme podemos visualizar no gráfico 3.

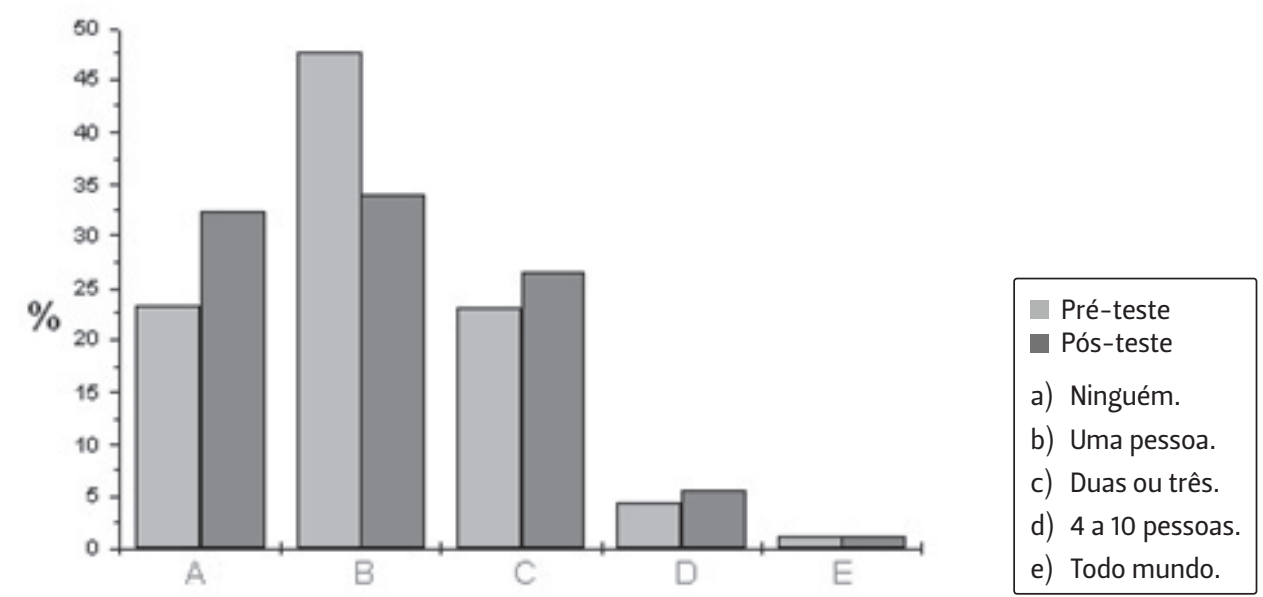

Gráfico 3 - Tem alguém da sua classe que o incomoda com brincadeiras, ameaças, empurrões ou outras formas que o deixam chateado?

Entretanto, é possível constatar que a resposta "ninguém" apresentou aumento, ao passo que a resposta "uma pessoa" diminuiu de $47,7 \%$ para $34,01 \%$. Ainda que tais diferenças não sejam estatisticamente significativas, elas denotam que haveria um sinal de mudança nessas relações. Pesquisas apontam que o sentimento de empatia - a sensibilidade pela dor de um colega - é característico da criança pequena; para que tal sentimento se estruture como um valor, é necessário que haja a convivência com o outro, a experiência de dizer o que sente e ouvir do outro suas mágoas, suas dores (LA TAILLE, 2006; TOGNETTA, 2011). Quando proporcionamos a vivência entre iguais, percebemos o que também apontam vários estudos: as crianças tendem a responder de maneira mais sensível aos pares que lhes são semelhantes (TOGNETTA, 2011). Nesse sentido, crianças que experimentam vivenciar e expressar suas emoções, reconhecendo-as, podem tornar-se mais empáticas com os outros.

Outra pergunta feita no pré e no pós-teste foi relativa ao sentimento de solidão. Sabemos da importância de momentos 
consigo mesmo para que se constituam personalidades equilibradas, conforme já defenderam diferentes estudos (CHITMAN, 1998; LA TAILLE, 1998, TOGNETTA, 2009), mas o que desejávamos obter neste questionário eram respostas sobre o que as crianças sentem nas ocasiões em que, intencionalmente, são deixadas de lado pelo próprio grupo ao qual pertencem. Para tanto, interrogamos: "Alguma vez você já se sentiu sozinho no recreio porque seus amigos não quiseram brincar ou conversar com você?". Os resultados podem ser visualizados no gráfico 4 .

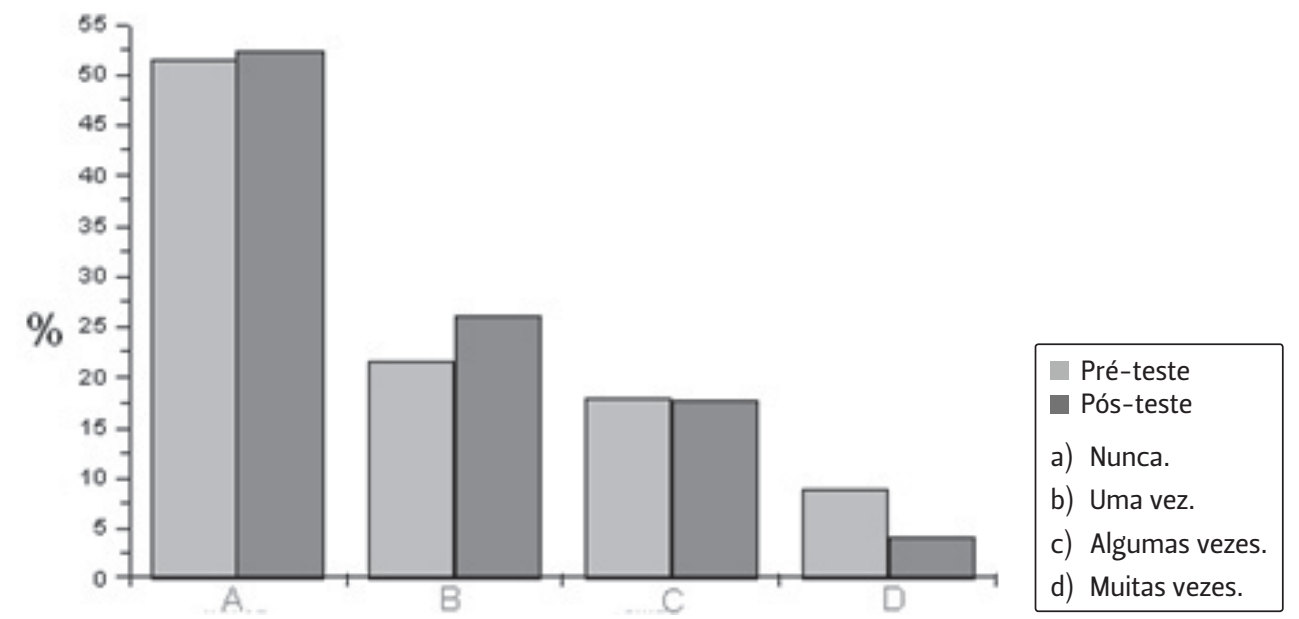

Gráfico 4 - Alguma vez você já se sentiu sozinho no recreio porque seus amigos não quiseram brincar ou conversar com você?

Notamos no gráfico, comparando o pré e o pós-teste, uma diminuição $(4,82 \%)$ estatisticamente comprovada da porcentagem de crianças que afirmaram sentirem-se sozinhas no recreio $(p<0.01)$. Por certo, quando o ambiente escolar valoriza oportunidades em que os alunos podem falar de si, ele favorece o autoconhecimento e, com isso, crianças e adolescentes aprendem a controlar suas emoções e conhecer os sentimentos dos outros, buscando o equilíbrio entre o bem para si e para os demais. Assim também se torna possível a tomada de consciência das diferenças individuais (TOGNETTA, 2009).

Por certo, as histórias utilizadas puderam, de forma prazerosa, estabelecer uma discussão moral, um diálogo, possibilitando a transposição de situações hipotéticas para a vida real. Ao refletir sobre as ações das personagens, as crianças tiveram a oportunidade de construir suas opiniões e ouvir as dos outros, bem como ponderar sobre os momentos em que se sentiram mal por terem sido deixadas de lado ou quando o fizeram a outrem, tal como acontecia também no enredo das histórias. 
0 modelo atual proposto pelo ambiente escolar, na maioria das vezes, não proporciona para as crianças a melhor oportunidade de desenvolvimento, pois mantém um regime individualista, limitando as capacidades de desenvolvimento afetivo e dificultando, assim, as relações com os demais indivíduos (MANTOVANI DE ASSIS; ASSIS, 2002; GARCIA, 2007; GOERGEN 2007; LEME, 2006; TOGNETTA, 2009; TOGNETTA; VINHA, 2008). É sabida, portanto, a necessidade de reorganizar esse ambiente escolar. Um dos fatores relevantes para isso é a realização dos trabalhos em grupo que tanto favorecem a interação entre os alunos, permitindo a descentração e a superação do pensamento egocêntrico natural da criança, bem como a colaboração e a melhoria na relação entre os sujeitos. Num trabalho em grupo, é preciso coordenar pontos de vista e buscar soluções possíveis para se resolver um problema; além disso, para se chegar a um objetivo comum, muitas vezes é preciso também ajudar os companheiros de grupo na busca pela solução (MANTOVANI DE ASSIS; ASSIS, 2002). Na verdade, o ponto primordial do trabalho em grupo não é a solução da atividade proposta, mas sim a garantia da oportunidade de interação, colaboração, reciprocidade entre os pares e tomada de consciência do próprio erro no processo de busca pela solução conjunta.

Nesse sentido, perguntamo-nos: o que poderia ser mudado com a implantação do referido projeto? Para analisar a efetividade do trabalho em grupo, interrogamos as crianças: "Você já fez ou faz trabalhos em pequenos grupos na sua sala de aula?". A fim de efetuar a comparação entre os dois momentos e aplicar um teste estatístico, foi necessário reagrupar as respostas dos sujeitos que assinalaram mais de uma alternativa. Para cada sujeito, foram consideradas sua resposta e a alternativa que seria superior, segundo o critério de maior frequência e de autonomia nos processos de escolha dos companheiros nos trabalhos em grupos. A seguir, os resultados obtidos podem ser visualizadas no gráfico 5 .

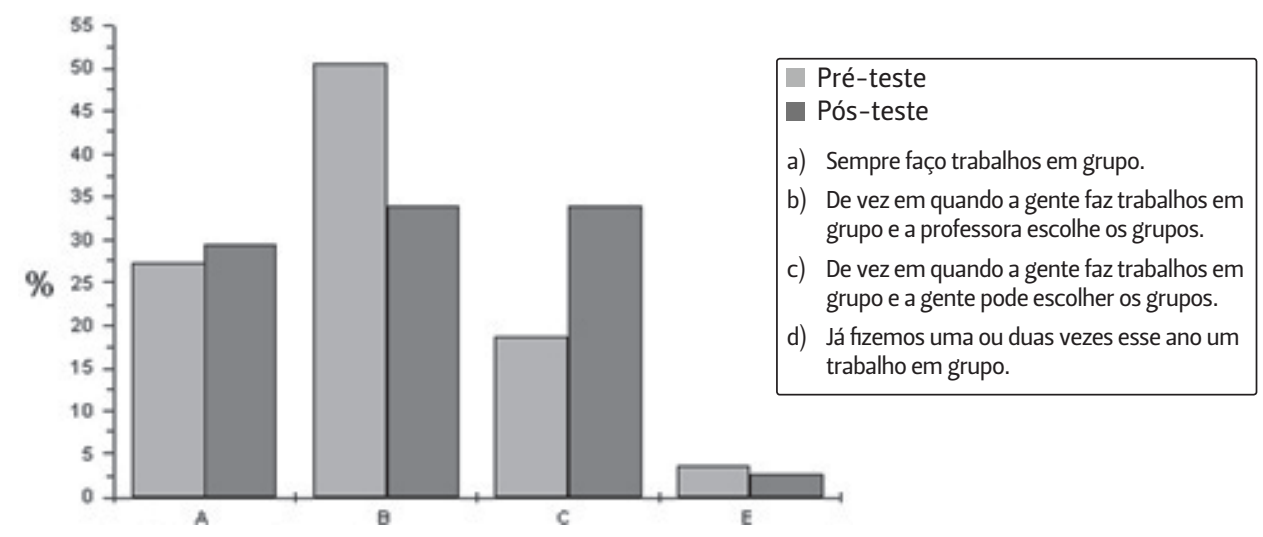

Gráfico 5 - Você já fez ou faz trabalhos em pequenos grupos na sua sala de aula? 
Com auxílio do teste de simetria, constatamos mudanças significativas principalmente nas alternativas $b$ e $c(p<0.1)$, o que significa que houve maior possibilidade de escolha pelos participantes quanto aos grupos nos quais poderiam participar e menor intervenção da professora a esse respeito. No pré-teste, destacou-se a alternativa $b$, em que os trabalhos em grupo eram feitos, mas quem escolhia os alunos era o educador; após a intervenção, houve uma queda significativa de $16,53 \%$ nessa resposta. Em contrapartida, ocorreu o crescimento de 15,32\% da categoria $c$, em que os próprios alunos escolhiam seus grupos. Vale lembrar que, a fim de propiciar a interação com novos colegas e o aumento do círculo de amizades, é necessário o equilíbrio entre a escolha do grupo ora pelo educador, ora pelos alunos, visando alternar entre a rotatividade imposta e o desejo dos alunos em ficar sempre com os mesmos amigos. Contudo, o que queremos dizer é que os trabalhos em grupo, notadamente na perspectiva construtivista, são momentos também de escolhas pessoais e trocas de pontos de vista.

\section{Os sentimentos expressos com relação à escola}

Perguntamos às crianças como elas se sentiam quando estavam na escola. Entre as opções possíveis, estavam as seguintes respostas: triste, alegre, chateado, com medo, com vontade de ir embora, irritado, entusiasmado e animado. Nota-se que não houve um equilíbrio entre sentimentos positivos e negativos, sendo estes últimos mais presentes nas alternativas de escolha; ainda assim, notou-se uma mudança significativa que demonstra certo bemestar na escola depois do trabalho realizado. Vejamos os resultados no gráfico 6 .

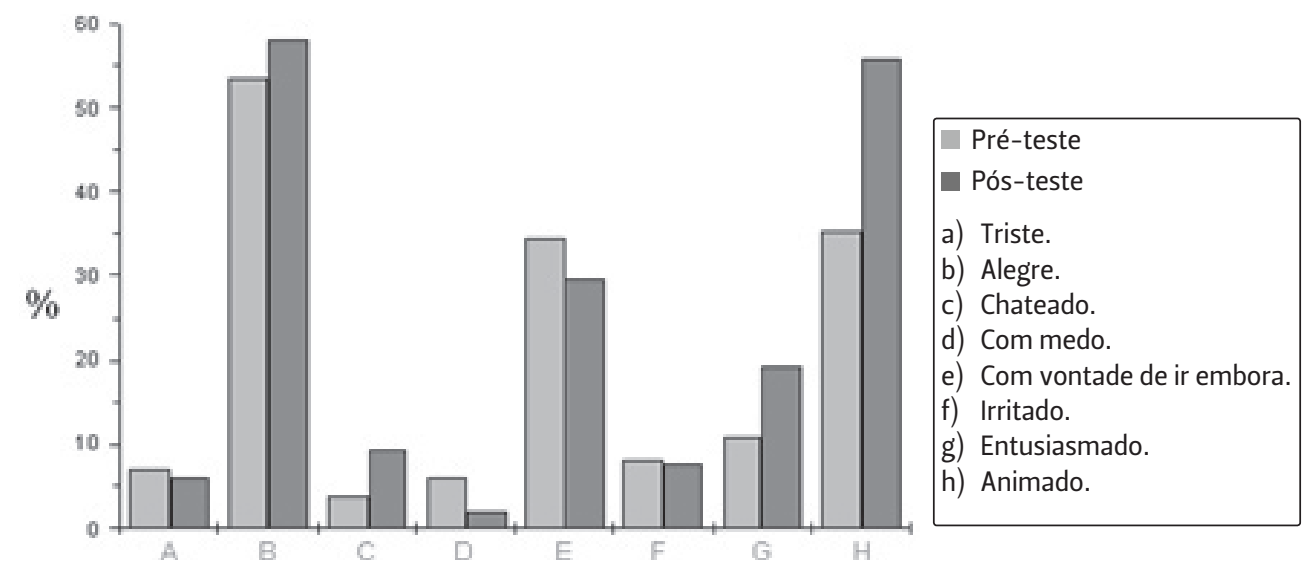

Gráfico 6 - Como você se sente quando está nas aulas? 
A partir do gráfico constatamos o aumento dos sentimentos que representam a satisfação e o desejo de permanecer na escola e querer participar das atividades propostas, o que se evidencia na relação entre as alternativas "alegre" (4,4\%), "entusiasmado" $(8,4 \%)$ e "animado" $(20,48 \%)(\mathrm{p}<0.1$ para "animado" e para "entusiasmado"). A resposta "com vontade de ir embora" foi reduzida depois da implantação do ambiente cooperativo. Tais dados parecem reiterar que a participação efetiva nos trabalhos em grupo e a liberdade que o aluno tem para dizer como se sente diante do conflito em sala de aula são representadas nessa mudança.

Chamou-nos a atenção o fato de que, na alternativa "chateado", houve um aumento significativo das respostas de acordo com a aplicação do teste estatístico de McNemar $(p<0.1)$. Contudo, se juntarmos os sentimentos que podem ser considerados negativos quanto ao que as crianças sentem pela escola, encontramos um percentual menor no pós-teste. Outro dado que nos permite afirmar o quanto a melhora nas relações interpessoais pôde ser notada no pós-teste é a diminuição do que os alunos apontaram como medo. Pela aplicação do teste de $\operatorname{McNemar}(p<0.1)$, obtivemos uma redução significativa de tais respostas, indicando que os alunos parecem ter ganhado maior liberdade para expressar sentimentos e resolver seus conflitos, bem como estabelecido uma relação de confiança com a autoridade, o que dispensaria o medo da punição e do castigo.

\section{Considerações finais}

Há cerca de 40 anos, Piaget afirmou que o direito à educação não é apenas o simples direito de frequentar uma escola; é também, diria ele, "a educação ao pleno desenvolvimento da personalidade, o direito de encontrar nessas escolas tudo aquilo que seja necessário à construção de um raciocínio pronto e de uma consciência moral desperta" (PIAGET, 1973, p. 53).

Não é difícil concluir que tal direito de desenvolvimento pleno da personalidade é alvo quase inatingível de nossas escolas na atualidade, haja vista o grande número de situações de violência, de indisciplina e de outros tantos problemas que são noticiados pela mídia. 0 desejo de formar personalidades éticas existe, mas parece haver uma lacuna entre os nobres objetivos que se traçam nos planos escolares e sua efetivação na prática cotidiana. Como 
ultrapassar essa lacuna?

Esta pesquisa buscou lançar algumas luzes para que se possa vencer esse desafio de transformar a prática da sala de aula que alcance o objetivo de que as relações interpessoais sejam de melhor qualidade no interior da escola. Ainda que pequenas, tais luzes sinalizam ações que podem ser realizadas no cotidiano escolar a partir de materiais que já estão disponíveis.

É sabido que a simples utilização de um recurso didático não é suficiente para atingir o objetivo proposto, que é o de educar moralmente. Vimos que não se trata de escolher qualquer livro cuja intenção moralizante esteja presente, mesmo que não de modo explícito. A escolha primeira é por um material que seja fundamentado empiricamente e que permita ao leitor a experiência da reflexão sobre aquilo a que faz alusão. Os livros utilizados, neste sentido, cumprem esse papel por proporcionarem às crianças a possibilidade de se posicionarem moralmente diante de si (pelo autoconhecimento), diante da autoridade (pelo respeito mútuo) e diante dos pares por meio da cooperação. Mas não seriam suficientes se apenas forem entregues nas mãos das crianças. A proposta de autoconhecimento, de conhecimento dos sentimentos dos outros e de busca por relações mais equilibradas, nas quais a tolerância, o respeito e a justiça estejam presentes, só é possível ser efetivada em um ambiente em que se possa vivenciar essas experiências nos conflitos cotidianos e, portanto, nos trabalhos em grupo, nas escolhas das atividades, no tratamento recebido dos professores e no encaminhamento das regras, fato destacado pela formação de educadores que acompanhou o trabalho em questão.

Os sentimentos expressos pelas crianças depois da implantação do projeto denotam que a experiência de convivência com os iguais - e, quem sabe, com os professores - teve melhor qualidade, pois foi regida pela cooperação e pelo respeito mútuo. Por certo, a transformação que pretendemos para a escola não é uma tarefa fácil. Mudar esse ambiente geralmente é trabalhoso. Lewis (1999, p. 270) nos lembraria que as pessoas estão sempre se adaptando aos seus ambientes e que, à medida que esses ambientes se transformam, as pessoas também mudam: "Mudamos para melhor sempre que o melhor existe à nossa volta. Quando o que é bom à nossa volta torna-se ruim, nós mudamos de novo". Mesmo que se trate de um trabalho árduo, o autor afirma que o motor das mudanças está também no ambiente em que vivemos.

Assim, o contexto da sala de aula é imprescindível na formação das crianças. Este era o principal objetivo do curso ministrado 
aos professores: a possível mudança para um ambiente em que a cooperação esteja presente e em que se considere que as relações entre pares podem transformar-se em mais harmônicas quando os problemas são tratados com quem se deve e as crianças têm oportunidades para falar o que pensam e o que sentem. Os resultados encontrados na presente investigação corroboram essas premissas que estiveram presentes durante a formação de professores.

Nota-se, portanto, o importante papel que cabe à escola, à educação: criar oportunidades para que haja o desenvolvimento moral infantil, uma vez que as crianças e os jovens passam grande parte da vida dentro dos muros escolares e ali se formam sua sensibilidade e seus modos de pensar e agir. No contexto escolar, não há como separar o aprendizado de disciplinas e a formação moral, uma vez que as relações entre professor e aluno, as avaliações, os livros didáticos e as discussões carregam e transmitem ideais de mundo e valores. Tal como nos lembra Goergen (2007, p. 746), "parece razoável que isso não aconteça de forma inconsciente e difusa pelo assim chamado currículo oculto, mas que seja explicitada, discutida e orientada para a formação de um sujeito moral, autônomo, crítico e responsável".

Assim, percebe-se a importância de um ambiente sociomoral cooperativo que propicie a expressão dos sentimentos e a tomada de consciência dos valores morais a partir de um trabalho constante de reflexão sobre os conflitos cotidianos, o que pode ocorrer por meio da aventura de hipoteticamente vivenciar e aprender com a vida de personagens trazidos da literatura infantil. Para que os professores assumam o papel de formadores morais, é também importante que haja uma educação, um estudo voltado para esse trabalho, bem como a experiência de um ambiente de cooperação e respeito mútuo entre eles próprios.

A atual pesquisa nos permitiu vislumbrar uma das possibilidades de formar moralmente nossos alunos e obter melhoras na convivência entre pares via literatura infantil. Os resultados reverberam o necessário olhar à formação de professores e a superação de práticas alicerçadas no senso comum para se resolverem os problemas cotidianos nas relações entre as crianças. Também apontam para um caminho convergente com algumas alternativas que se tem visto em outros países, que concedem a importância devida à educação: é imprescindível a formação de educadores que prezem pela formação ética de suas crianças e que estudem para bem fazê-lo. Da mesma forma, é preciso que se promovam em nossas escolas projetos de convivência em 
que as relações interpessoais estejam em pauta. Em termos de políticas públicas, os resultados ressaltam a necessária e urgente revisão das formas pelas quais nossos professores têm educado moralmente seus alunos, pois assim talvez se possa repensar a urgência da formação de professores.

Enfim, conforme salienta Goergen (2007, p. 760) "o caminho certamente não é nem curto nem fácil". Entretanto, é possível.

\section{REFERÊNCIAS}

BAGAT, Matilde P. Annotazzioni e riflessioni sulle moral autonomie. Attualitá in Psicologia, Roma, v. 1, n. 2, p. 49-56, 1986.

CHITMAN, Lilian Kos. A solidão das crianças. Rio de Janeiro: Editora Rosa dos Tempos, 1998.

CLARE, Lindsay; GALLIMORE, Ronald. Using moral dilemmas in children's literature as a vehicle for moral education and teaching reading comprehension. Journal of Moral Education, v. 25, n. 3, p. 325-342, 1996.

COELHO, Nelly Novaes. A literatura infantil: história, teoria e análise. São Paulo: Quiron/Global, 1982.

Literatura infantil: teoria, análise e didática. 7. ed.

São Paulo: Moderna, 2000.

DEBARBIEUX, Éric. Violência na escola: um desafio mundial? Lisboa: Instituto Piaget, 2006.

DUBET, François. Quando o sociólogo quer saber o que é ser professor. Revista Brasileira de Educação, n. 5 e 6, p. 222231, 1997.

EPSTEIN, Ann S. How planning and reflection develop young children's thinking skills. Young Children, v. 58, n. 5, p. 2836, 2003.

GARCIA, Joe. Currículo e questões de indisciplina. In: CONGRESSO NACIONAL DE EDUCAÇÃO - EDUCERE, 7., 2007, Curitiba. Anais... Curitiba: Editora Universitária Champagnat, 2007. p. 1-12. 
GOERGEN, Pedro. Educação moral hoje: cenários, perspectivas e perplexidades. Revista Educação Social, v. 28, n. 100, Especial, p. 737-762, 2007.

JALONGO, Mary. Stories that teach life lessons. Scholastic Parent \& Child, v. 12, n. 2, p. 36-42, 2004.

KROGH, Suzanne Lowell; LAMME, Linda Leonard. Children's literature and moral education. Young Children, v. 40, p. 4851, 1985.

LA TAILLE, Yves de. Limites: três dimensões educacionais. São Paulo: Ática, 1998.

Moral e ética: dimensões intelectuais e afetivas.

Porto Alegre: Artmed, 2006.

LEME, Maria Isabel da Silva. Convivência, conflitos e educação nas escolas de São Paulo. São Paulo: ISME, 2006.

LEWIS, Michael. Curar ou cuidar. In: Alterando o destino: por que o passado não prediz o futuro. Tradução de Dinah de Abreu Azevedo. São Paulo: Moderna, 1999. p. 129 138.

LOWE, Danielle F. Helping children cope through literature. Forum on Public Policy Online, v. 1, 2009.

MANTOVANI DE ASSIS, Orly Zucatto; ASSIS, Maria Luiza Camargo de (Orgs.). PROEPRE: fundamentos teóricos da educação infantil. Campinas: LPG/UNICAMP, 2002.

MENIN, Maria Suzana de Stefano. Desenvolvimento moral: refletindo com pais e professores. In: MACEDO, Lino de (Org.). Cinco estudos de educação moral. São Paulo: Casa do Psicólogo, 1996. p. 37-104.

MEYER, Richard J. Stories to teach and teaching story: the use of narrative in learning to teach. Language Arts, v. 72, n. 4, p. 276-286, 1995.

OLIVEIRA, Aurea Maria de. Literatura infantil e desenvolvimento moral: a construção da noção de justiça em crianças pré-escolares. Dissertação (Mestrado em Educação) - Universidade Estadual de Campinas, Campinas, 1994. 
. Literatura infantil: o trabalho com o processo de construção de valores morais, na educação infantil. Educação: Teoria e Prática, v. 16, n. 28, p. 101, 121, 2007.

PIAGET, Jean. Seis estudos de psicologia. Rio de Janeiro: Forense, 1969.

Para onde vai a educação? Tradução de Ivette Braga. Rio de Janeiro: Livraria José Olympio Editores, 1973.

O juízo moral na criança. São Paulo: Summus Editorial, 1994.

ROSÁRIO, Pedro Sales L. de Fonseca et al. Autorregulação da aprendizagem a partir de estórias: investigação no préescolar. In: CONGRESSO INTERNACIONAL DE APRENDIZAGEM NA EDUCAÇÃO DE INFÂNCIA - CIANEI, 1., 2005, Porto. Actas... Porto: Edições Gailivro, 2005. p. 1-10.

SAS System for Windows (Statistical Analysis System), versão 9.2. SAS Institute Inc, 2002-2008, Cary, NC, USA.

TOGNETTA, Luciene Regina Paulino. A formação da personalidade ética: estratégias de trabalho com afetividade na escola. Campinas: Mercado de Letras, 2009.

Suplemento especial para pais e professores: caixa de segredos. Americana: Adonis, 2011.

TOGNETTA, Luciene Regina Paulino; VINHA, Telma Pileggi. Valores em crise: o que nos causa indignação? In: LA TAILLE, Yves de; MENIN, Maria Suzana de Stefano. Crise de valores ou valores em crise? Porto Alegre: Artmed, 2008. p. 15-42.

WHITEBREAD, David et al. Developing independent learning in the early years. Education, v. 33, n. 1, p. 40-45, 2005.

ZILBERMAN, Regina. A literatura infantil na escola. São Paulo: Global, 2003. 